\title{
SANGGAH KAMULAN \\ SEBAGAI MEDIA PEMUJAAN PADA MASYARAKAT HINDU DI KOTA MATARAM: SEBUAH KAJIAN FILSAFAT
}

\author{
John Abraham Ziswan Suryosumunar, I Ketut Narwadha \\ IAHN Gde Pudja Mataram \\ suryosumunar0202@gmail.com, narwadha.ikt@gmail.com
}

\begin{abstract}
Abstrak
Penelitian ini dimaksudkan untuk melakukan kajian tentang sanggah kemulan yang digunakan sebagai media untuk melakukan pemujaan oleh masyarakat Hindu di Kota Mataram dalam perspektif filsafat. Penelitian ini dirancang dalam penelitian deskriptif kualitatif. Berdasarkan hasil penelitian ada tiga temuan penelitian. Pertama, bentuk sanggah kamulan yang ada pada masyarakat Hindu di Kota Mataram ada yang berupa bangunan rong tiga saka dua, ada rong tiga saka nem, rong tiga turus lumbung, dan ada berupa rong kalih. Bentuk-bentuk tersebut sangat erat kaitannya dengan keyakinan (sraddha) dari umat Hindu sebagai media pemujaan terhadap Manifestasi Ida Sang Hyang Widhi maupun Hyang Dewa Pitara/Leluhur. Kedua, fungsi sanggah kamulan berupa rong tiga adalah sebagai stana Ida Sang Hyang Widhi (Tuhan) wujud sebagai Sang Hyang Tri Atma : Atma-SiwatmaParatma. Wujud sebagai Sang Hyang Tri Purusa: Siwa-Sada Siwa-Parama Siwa. Sesuai pula dengan Brahma-Wisnu-Iswara. Siwa berfungsi sebagai Guru, maka Hyang Kamulan juga disebut Batara Guru : Guru Purwam (Parama Siwa), Guru Madyam (Sada Siwa), Guru Rupam (Siwa). Dengan demikian sesungguhnya yang dipuja pada Sanggah Kamulan adalah Ida Sang Hyang Widhi dalam wujud sebagai Sang Hyang Tri Atma, Sang Hyang Tri Purusa (Bhatara Guru) dan Sang Hyang Tri Murti disamping juga sebagai media pemujaan Hyang Dewa Pitara/Leluhur. Ketiga, makna filosofis sanggah kamulan berkaitan dengan hakikat dasar yang menjadi landasan dalam pembangunan pelinggih sanggah kamulan yakni sebagaimana gagasan Mpu Kuturan yang telah meminit palinggih Sanggah Kamulan Rong Tiga merupakan manifestasi Ida Sanghyang Widhi dimana Brahma sebagai pencipta dengan lamak warna merah, Wisnu sebagai pemelihara dengan lamak warna hitam dan Iswara sebagai pemralina dengan lamak warna putih dinamakan Sanghyang Tri Murti.
\end{abstract}

\section{Kata Kunci: Sanggah Kamulan, Filsafat, Kota Mataram}

\section{Pendahuluan}

Di setiap pekarangan perumahan masyarakat Hindu Bali yang ada di Kota Mataram Lombok, pada arah kaja kangin (Timur Laut) terdapat areal suci yang dinamakan "Sanggah" atau "Merajan". Pada tempat suci tersebut ada beberapa bangunan suci yang digunakan sebagai media untuk ngelinggihang (menstanakan) manifestasi Ida Sang Hyang Widhi beserta para leluhur yang telah disucikan. Agak di tengah menghadap ke barat ada sebuah palinggih berongga atau beruang tiga dinamakan Sanggah Kamulan.

Keberadaan Sanggah kamulan sudah ada dari sejak Kerajaan Mentaram berdiri dengan eksis di wilayah Lombok Barat dibawah kepemimpinan Raja Karangasem Bali diseputaran abad ke 16-17. Mengenai bentuk Sanggah Kamulan di wilayah Kota Mataram tampak sama 


\section{J. A. Z. Suryosumunar\&I Ketut Narwadha-Sanggah Kamulan sebagai Media Pemujaan pada Masyarakat Hindu di Kota Mataram: Sebuah Kajian Filosofis}

yang kemungkinan menyesuaikan dengan kondisi dan situasi pada waktu itu atau "nganutin desa kala patra" dan terwarisi dari sejak itu sampai saat ini. Hal ini menjelaskan prinsipprinsip kebudayaan yang merupakan ekspresi dari etos, tradisi, estetika, ide-ide yang terlontar sebagai sebuah pandangan (Noorzeha, 2019). Sanggah kamulan tersebut merupakan sebuah bangunan yang berbentuk "limasan" dengan "saka" atau tiang enam dimana dua saka didepan sebagai penyangga bagian depan sedang empat saka ada ditengah dan dibelakang selain sebagai penyangga juga untuk membuat "dua Blegadu". "Blegadu" dibawah berstatus penguat bangunan palinggih dan "Blegadu" di atas dibagi tiga ruang dengan menempatkan atau membuat sebuah "pelangkiran" ditengah dengan kedudukan sedikit lebih tinggi dari ruang sebelah kanan dan kiri. Selain itu, dipasangkan kain atau "lamak" dengan warna merah disebelah kanan manifestasi Ida Sanghyang Widhi yakni Brahma sebagai pencipta. Disebelah kiri warna hitam yakni Wisnu sebagai pemelihara dan yang ditengah berwarna putih yakni Iswara atau Siwa atau Rudra sebagai pelebur.

Orang tua menjelaskan kepada anak cucu bahwa Sanggah Kamulan dengan "lamak" merah putih hitam merupakan kamulan hidup. Maksudnya, kamulan atau pokok atau asal manusia ada dari tiga kondisi yakni manusia itu ada (lahir), hidup dan mati atau Utpeti - Stiti Pralina beraksara Ang, Ung, Mang, dewanya Brahma, Wisnu dan Iswara manifestasi dari Ida Sanghyang Widhi dan orang tua mengatakan, siapapun (Hindu Bali Lombok) bisa atau boleh"ngaturang sembah bhakti" di Sanggah Kamulannya siapa saja.

Jaman telah berubah dan terus berkembang, lalu lintas perpindahan penduduk antar pula uterus berjalan secara cepat dengan membawa perilaku kehidupan dari tempat asal. Berakibat kearifan lokal mulai bergeser setapak demi setapak, lambat tapi tampak meyakinkan terlebih mengingat dan menyadari dimana keberadaan masyarakat Hindu Bali di Kota Mataram Lombok berasal dari Bali.

Bila diperhatikan dengan seksama tentang bentuk Sanggah kamulan yang disuguhkan agak kecil, spesifik dan bernilai seni sehingga tampak megah. Ketiga ruang kecilkecil berpintu, dua saka penyangga di depan tetap seperti semula sedang "blegade" dibawah dinaikkan berjarak sekitar 20-25 cm dibawah blegade rong sanggah. Keempat saka di belakang diperpendek dan didudukan di atas bataran campuran pasir semen dan sejenisnya. Bentuk Sanggah kamulan seperti itu dinyatakan sebagai tempat "malingga" atau "malinggih" Hyang dewa yang empunya Sanggah. 
Mencermati masalah tersebut membuat masyarakat Hindu Bali yang ada di NTB khususnya Kota Mataram menjadi riskan untuk "ngaturang bhakti” (sembahyang) di Sanggah Kamulan yang lainnya. Penyuguhan kondisi seperti itu perlu dilakukan penelitian sebagai upaya untuk membedah atau mengungkap dasar filsafat keagamaan yang terkandung dalam Sanggah kamulan sebagai media pemujaan atau sarana pengungkapan Sradha Bhakti masyarakat Hindu Bali di Kota Mataram Lombok.

Menurut Ardhi Wirawan (2014; 7), kerajaan yang ada di Lombok juga memiliki takaran kehidupan sosio kultural yang digunakan untuk menata kehidupan sosial, budaya dan praktek beragama. Dibalik keberadaan tatanan tersebut ada cara pandang yang digunakan untuk membangun tata perilaku kehidupan sosial masyarakat baik yang tertulis maupun yang tidak tertulis. Cara pandang tesebut memiliki relasi yang erat dengan sistim filosofi yang dimiliki oleh masyarakat tersebut.

Berkaitan dengan latar belakang di atas, dalam penelitian ini dirumuskan tiga permasalahan untuk ditemukan jawabannya. Pertama, bagaimana bentuk pelinggih Sanggah Kamulan pada masyarakat Hindu etnis Bali di Kota Mataram? Kedua, apa fungsi pelinggih Sanggah Kamulan dalam kehidupan beragama pada masyarakat Hindu etnis Bali di Kota Mataram? Ketiga, apa makna filosofis dari pelinggih Sanggah Kamulan pada masyarakat Hindu etnis Bali di Kota Mataram Lombok NTB? Penelitian ini secara umum bertujuan untuk melakukan analisis filosofis Sanggah Kamulan sebagai media pemujaan yang ada di lingkungan keluarga umat Hindu di Kota Mataram. Hal tersebut berkakitan dengan warisan yang dikonsepkan oleh Mpu Kuturan dalam menata kehidupan beragama umat Hindu di Bali pada masa kesejarahan melalui konsep Tri Murti dalam lingkungan keluarga Hindu diwujudkan dalam simbol Sanggah Kamulan.

\section{Metodologi Penelitian}

Penelitian secara kualitatif adalah tampilan yang berupa kata-kata lisan atau tulisan yang dicermati sampai detail agar dapat diungkap apa yang tersirat dalam dokumen atau bendanya (Arikunto, 2010 :61). Pendapat lain mengatakan, metode penelitian kualitatif adalah metode penelitian yang berlandaskan pada tingkat post positivism digunakan untuk meneliti pada obyek yang alamiah dimana peneliti adalah sebagai instrument kunci. Teknik pengumpulan data dilakukan secara gabungan, analisis data bersifat induktif/kualitatif dan hasil penelitiannya lebih menekankan makna daripada generalisasi (Sugiyono, 2013 : 9). 


\section{J. A. Z. Suryosumunar\&I Ketut Narwadha-Sanggah Kamulan sebagai Media Pemujaan pada Masyarakat Hindu di Kota Mataram: Sebuah Kajian Filosofis}

Metode penelitian kuantitatif adalah metode penelitian yang berdasarkan pada filsafat positivism digunakan untuk meneliti pada populasi atau sampel tertentu. Pengumpulan data menggunakan instrument penelitian, analisis data bersifat kuantitatif/statistic dengan tujuan untuk menguji hipotesis yang telah ditetapkan (Sugiyono, $2013: 8$ ). Dalam penelitian yang berjudul : Kajian Filosofi Sanggah Kamulan Sebagai Media Pemujaan pada Masyarakat Hindu di Kota Mataram (Studi kasus fenomena yang berkembang dimasyarakat Hindu etnis Bali di Lombok NTB). Penulis dalam hal ini mempergunakan penelitian non eksperiment atau yang bersifat kualitatif.

Penelitian ini berlokasi di Lingkungan Pajang Barat Kelurahan Pejanggik Kecamatan Mataram Kota Mataram. Pemilihan lokasi ini dengan pertimbangan bahwa bentuk sanggah kamulan yang dimiliki oleh umat di lokasi tersebut menunjukkan adanya variasi. Pertama, ada yang memiliki sanggah kamulan yang masih asli warisan umat Hindu Bali Lombok sejak masa Kerajaan Mentaram. Kedua, ada bentuk sanggah kamulan yang telah mengikuti pola pembangunan rong tiga sebagai pengaruh umat Hindu Bali yang datang belakangan.

Dalam penelitian ini jenis data yang dipergunakan adalah data kualitatif. Data kualitatif adalah data dalam bentuk kata-kata atau pernyataan. Sedangkan data kuantitatif adalah data yang disajikan dalam bentuk angka-angka, terstruktur dan terkontrol. Sumber data merupakan informasi yang diterima baik dari informan primer ataupun informan sekunder. Sumber data primer adalah sumber data yang langsung memberikan data kepada pengumpul data (Sugiyono, 2009 : 93). Data primer dipergunakan oleh melalui observasi pada obyek dan wawancara kepada pemilik Sanggah Kamulan Rong Tiga. Wawancara ini dilakukan untuk memperoleh informasi yang berkaitan dengan makna dan filsafat akan keberadaan Sanggah Kamulan Rong Tiga. Sedangkan sumber data sekunder adalah merupakan sumber yang tidak langsung memberikan data kepada pengumpul data, misalnya lewat orang lain atau lewat dokumen yang ada (Sugiyono, 2009 : 193). Dan sekunder yang dimaksud yaitu data yang diperoleh dari instansi-instansi, lembaga dan orang lain yang dapat membantu dalam memperoleh informasi yang berhubungan dengan penelitian ini.

Penelitian ini menggunakan tiga teknik pengumpulan data, yaitu wawancara, observasi, dan dokumentasi. Wawancara itu merupakan pertemuan dua orang untuk bertukar informasi dan ide melalui melalui Tanya jawab, sehingga dapat dikonstruksikan makna dalam suatu topik melalui tanya jawab, sehingga dapat dikonstruksikan makna dalam suatu topik tertentu (Sugiyono, 2009 : 37). Ada tiga macam wawancara masing : wawancara terstruktur, 
wawancara semistruktur dan wawancara tidak terstruktur (Sugiyono, 2009 : 319). Wawancara terstruktur, digunakan sebagai teknik pengumpulan data bila peneliti atau pengumpul data telah mengetahui dengan pasti tentang yang akan diperolehnya. Wawncara semistruktur, dipergunakan dengan tujuan untuk menemukan permasalahan secara lebih terbuka dan pihak yang diajak wawancara diminta pendapat dan ide-idenya. Wawancara tidak terstruktur ialah wawancara yang bebas dimana peneliti tidak menggunakan pedoman wawancara yang telah tersusun secara sistem datanya.

Berkaitan dengan penelitian ini, peneliti mempergunakan observasi langsung yaitu mengumpulkan data dengan pengamatan langsung ke obyek yang diteliti dalam hal ini pada bangunan suci palinggih Sanggah Kamulan Rong Tiga untuk melakukan pencatatan dan untuk mengetahui keadaan tempat penelitian.

Dokumentasi ialah mencari data mengenai hal-hal atau variable yang berupa catatan, transkrip, buku, surat kabar, majalah, prasasti, notulen rapat, agenda dan sebagainya (Arikunto, 2010 : 274). Dokumen merupakan catatan peristiwa yang sudah berlalu, dimana dokumen bisa berbentuk tulisan-tulisan dan gambar. Berkaitan dengan penelitian yang peneliti lakukan dimana dokumen yang terkumpul berupa buku-buku tentang bangunan suci dan fhoto palinggih Sanggah Kamulan Rong Tiga.

Analisa data adalah merupakan proses mencari dan menyusun secara sistimatik data yang diperoleh dari hasil wawancara, catatan lapangan dan dokumentasi dengan cara mengorganisasikan data kedalam kategori menjabarkan kedalam unit-unit, melakukan sintesa menyusun kedalam pola, memilih mana yang penting dan yang akan dipelajari dengan membuat kesimpulan sehingga mudah dipahami oleh diri sendiri maupun orang lain (Sugiyono, $2009:$ 335).

Ada tiga proses analisis data dalam penelitian ini, yaitu reduksi data, display data, dan penyimpulan. Mereduksi data berarti merangkum, memilih hal-hal yang pokok, memfokuskan pada hal-hal yang penting, dicari tema dan polanya dan membuang yang tidak perlu. Reduksi data merupakan proses berpikir sensitive yang memerlukan kecerdasan dan kekuasaan serta kedalaman wawasan yang tinggi. Proses selanjutnya dalam analisis data setelah reduksi data adalah melakukan display data yaitu penampilan dan penyajian data. Data yang disajikan dalam bentuk data kualitatif maka data dapat berupa uraian singkat, bagan, hubungan antar kategori. Sugiyono $2009 ; 345$, mengisyaratkan sebagai langkah ketiga dari proses analisa data kualitatif yang menurut Miles dan Hubermnan adalah penarikan 


\section{J. A. Z. Suryosumunar\&I Ketut Narwadha-Sanggah Kamulan sebagai Media Pemujaan pada Masyarakat Hindu di Kota Mataram: Sebuah Kajian Filosofis}

kesimpulan dan verifikasi. Kesimpulan dalam penelitian kualitatif yang diharapkan adalah temuan baru yang sebelumnya belum pernah ada. Temuan dapat berupa deskripsi atau gambaran suatu obyek yang sebelumnya masih remang-remang atau gelap sehingga setelah diteliti menjadi jelas.

\section{Hasil dan Pembahasan Penelitian}

\section{Bentuk Pelinggih Sanggah Kamulan pada Masyarakat Hindu Etnis Bali di Kota Mataram Lombok NTB}

Pelinggih Sanggah Kamulan merupakan simbol kebesaran dan kemahakuasaan Ida Sanghyang Widhi sebagai sarana pemujaan mengaplikasikan Sraddha dan Bhakti masyarakat Hindu secara keseluruhan. Pelinggih Sanggah Kamulan merupakan gagasan brilyan seorang tokoh agama pada jamannya bernama Mpu Kuturan. Sanggah Kamulan adalah manifestasi kemaha kuasa-an Ida Sanghyang Widhi sebagai Brahma - pencipta, Wisnu pemelihara/pelindung, Iswara/Siwa/Rudra - pelebur. Ide cemerlang Mpu Kuturan dalam menyebar luaskan ajaran Siwa Sidhanta sebagai sarana mendekatkan diri sipenyembah (Manawa) dengan yang disembah (Madawa). Hanya saja dalam perjalanan waktu dan kemajuan dibidang ilmu pengetahuan yang menciptakan ahli pikir - ahli pikir kondang sepertinya ide cemerlang tersebut tidaklah semulus semurni tujuan gagasan awal yang menumbuhkan rasa kesatuan dan persatuan masyarakat Hindu secara keseluruhan. Ini sebagai hasil adanya berbagai macam tanggapan terhadap ide cemerlang Mpu Kuturan menyuguhkan makna ganda yang dapat memberi celah terjadinya kelompok-kelompok atau "soroh" yang mengklaim pelinggih Sanggah Kamulan atau Rong Kalih sebagai sthana "leluhur" siempunya Sanggah yang telah bersatu dengan asalnya (Ida Sanghyang Widhi).

Berkaitan dengan bentuk sanggah kamulan pada masyarakat Hindu etnis Bali di Lombok yang diwarisi sampai saat ini tidak sama persis. Ada yang menggunakan bentuk saka dua (dua buah pilar). Bentuk sanggah kamulan yang menggunakan saka dua dicirikan oleh pilar penyangga bangunan hanya ada dua buah yang berada di depan. Sedangkan rong tiga posisinya menempel pada tembok pada bagian belakang, seperti yang ditunjukkan pada Gambar 4.1 berikut ini. 


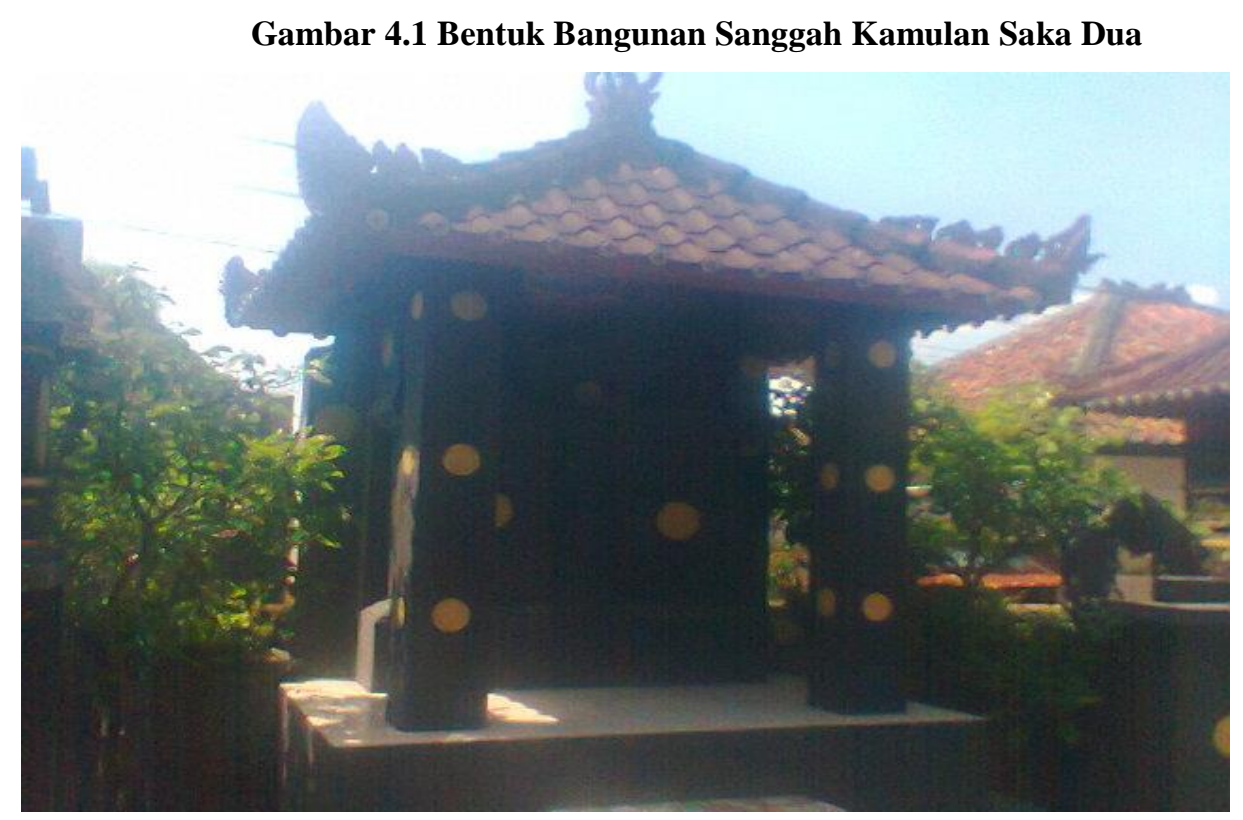

Sumber: Dokumentasi Narwada, Tahun 2016

Bentuk bangunan di atas merupakan bentuk sanggah kamulan yang menggunakan pola bangunan yang diwarisi dari masa kesejarahan pada masa kekuasaan Kerajaan Mentaram. Bentuk tersebut masih dijumpai dalam beberapa sanggah yang ada di Kota Mataram sampai saat ini. Bentuk tersebut secara umum tidak sama dengan bentuk pelinggih sanggah kamulan masyarakat Hindu di Bali belakangan ini.

Bentuk sanggah kamulan yang selanjutnya adalah bentuk yang telah mendapatkan pengaruh dari masyarakat Hindu di Bali yang datang belakangan. Ciri bentuk bangunan sanggah kamulan tersebut menggunakan saka nem (pilar enam buah). Sesuai dengan namanya, saka nem berarti jumlah pilar yang mendukung bangunan tersebut sebanyak enam buah. Bangunan tersebut seperti ditampilkan dalam Gambar 4.2 berikut ini.

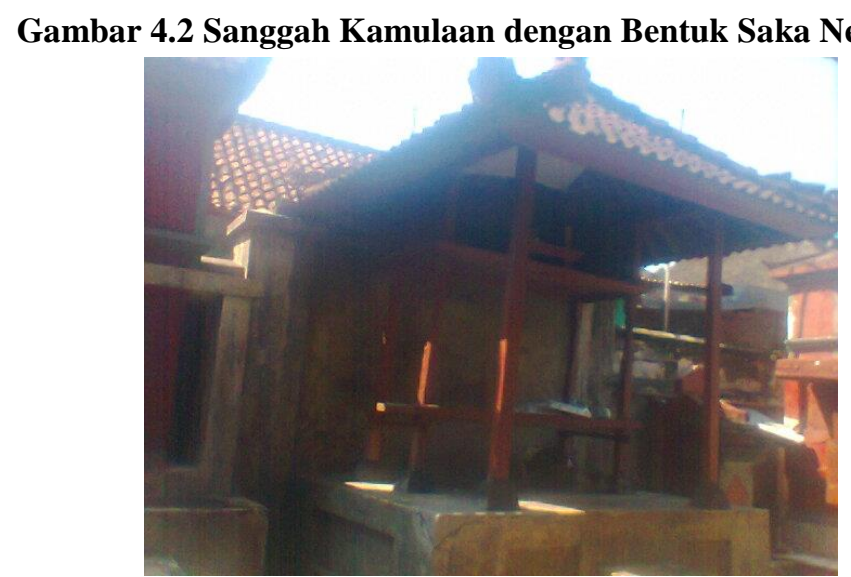

Sumber: Dokumentasi Narwada, Tahun 2016 


\section{J. A. Z. Suryosumunar\&I Ketut Narwadha-Sanggah Kamulan sebagai Media Pemujaan pada Masyarakat Hindu di Kota Mataram: Sebuah Kajian Filosofis}

\section{Gambar 4.3 Sanggah Kamulaan dengan Bentuk Rong Tiga Setelah Mendapat Pengaruh dari Bali Belakangan}

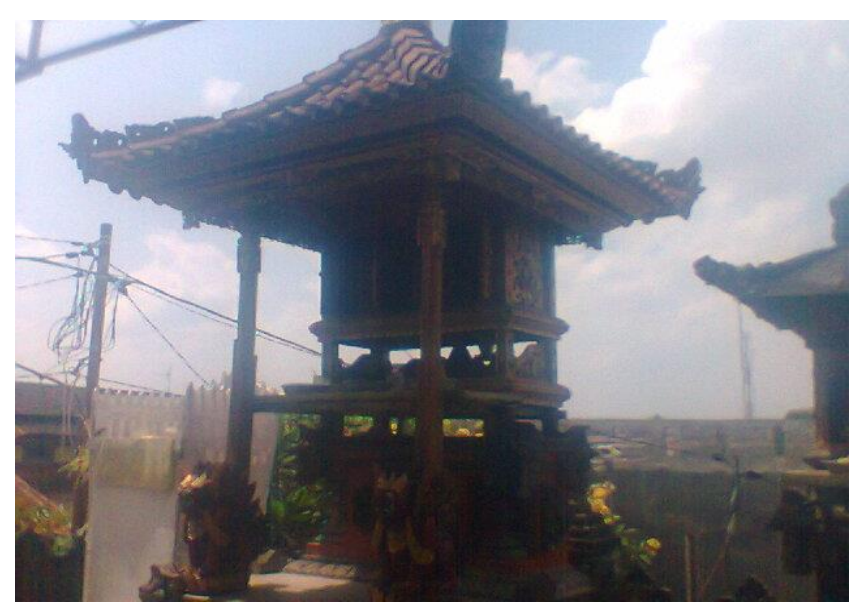

Sumber: Dokumentasi Narwada, Tahun 2016

Bentuk sanggah kamulan seperti pada Gambar 4.3 di atas merupakan bentuk yang telah mendapatkan pengaruh dari orang-orang Hindu yang berasal dari Bali yang datang belakangan. Dalam gambar tersebut ada rong tiga sebagai tempat untuk menstanakan simbol manifestasi Ida Sang Hyang Widhi maupun para leluhurnya.

Bentuk lainnya pelinggih sanggah kamulan yang ditemukan di lapangan adalah bentuk turus lumbung. Bentuk sanggah kamulan yang menggunakan turus lumbung cirinya terbuat dari kayu dapdap. Kayu ini juga dikenal dengan nama kayu sakti. Bentuk sanggah kamulan dengan mengunakan turus lumbung, seperti ditampilkan dalam Gambar 4.4 berikut ini.

Gambar 4.4 Bentuk Sanggah kamulan Berupa Turus Lumbung

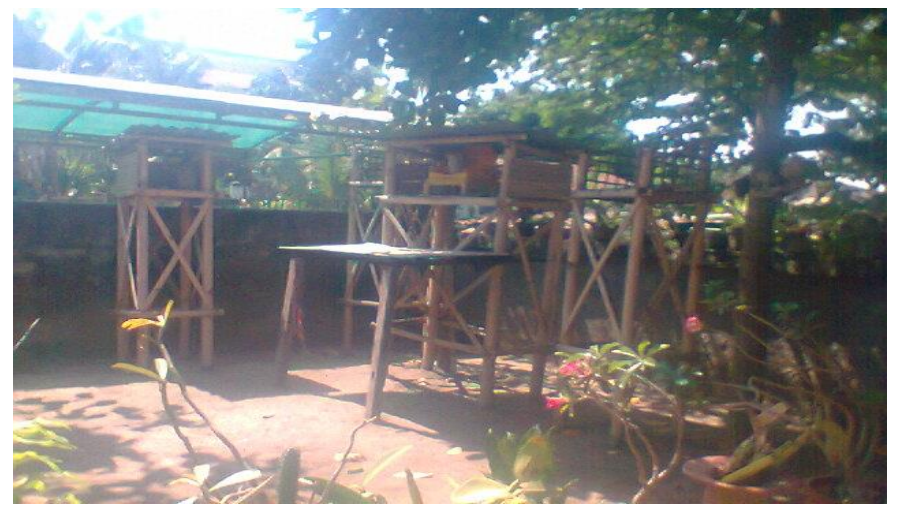

Sumber: Dokumentasi Narwada, Tahun 2016 
Bentuk Turus Lumbung dalam pembangunan pelinggih Sanggah Kamulan pada masyarakat Hindu di Kota Mataram juga masih bisa ditemukan. Umumnya bentuk turus lumbung digunakan bagi mereka yang masih dalam taraf perekonomian yang sederhana.

Selain berbentu rong tiga, ada juga bangunan untuk memuja para leluhur dengan menggunakan bentuk rong kalih. Rong kalih berarti ruang tempat menstanakan roh leluhur berjumlah dua buah. Bentuk palinggih rong kalih, seperti ditampilkan dalam Gambar 4.5 berikut ini.

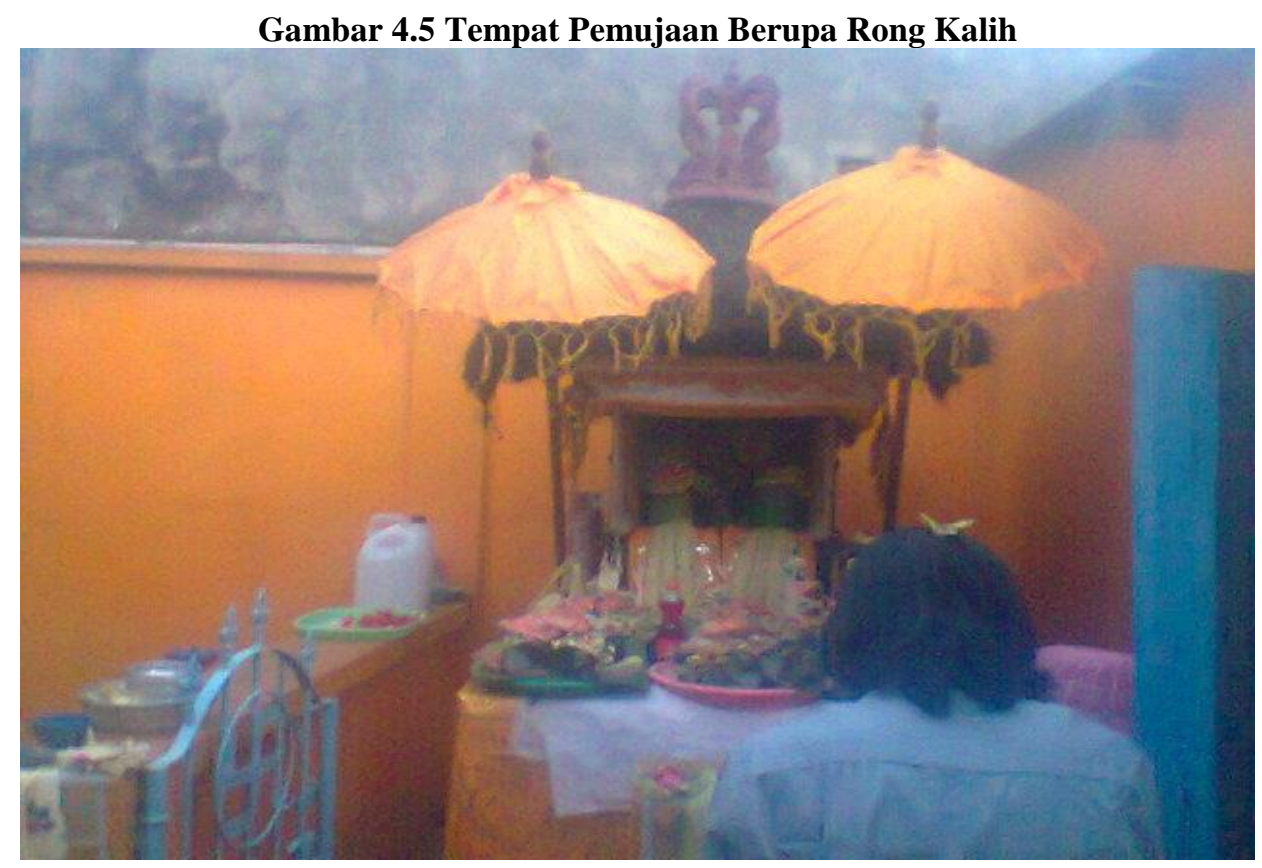

Sumber: Dokumentasi Narwada, Tahun 2016

Gambar 4.5 di atas memberikan deskripsi tentang keberadaan palinggih rong kalih sebagai tempat untuk melakukan pemujaan terhadap roh leluhur. Dalam palinggih rong kalih ruang tempat menstanakan roh leluhur ditempatkan dalam posisi yang horizontal. Posisi tersebut menunjukkan adanya kesetaraan penempatan antara purusa dan pradhana.

Adanya perbedaan-perbedaan bentuk pelinggih sanggah kamulan tersebut sangat ditentukan oleh sistem kepercayaan (sraddha) dari mereka yang membangun tempat suci tersebjut. Pada sisi lain, tanpa sadar membuat masyarakat lupa kepada lima pedoman hakiki agama Hindu yang disebut Panca Sradha. Menurut ketentuan agama, atma atau roh adalah seberkas cahaya Paratma yang segala maha, tidak ternoda apapun dan suci. Dan jika itu dibenarkan tentu saja masyarakat yang beruang saja dapat bersatu dengan asalnya (Sangkan paran). Sisanya masytarakat yang kurang beruntung dalam kehidupan atau melaksanakan 


\section{J. A. Z. Suryosumunar\&I Ketut Narwadha-Sanggah Kamulan sebagai Media Pemujaan pada Masyarakat Hindu di Kota Mataram: Sebuah Kajian Filosofis}

upacara Pitr secara "massal", maka atma atau rohnya hidup sebagai pengembara di dunia fana (niskala) karena belum mampu mensthanakan di Sanggah Kamulan atau Rong kalih untuk bersatu dengan asalnya (Ida Sanghyang Widhi).

\section{Fungsi Pelinggih Sanggah Kamulan Dalam Kehidupan Beragama pada Masyarakat} Hindu Etnis Bali di Kota Mataram

Mengenai fungsi akan keberadaan Sanggah kamulan berdasarkan beberapa data yang diperoleh, antara lain :

1. Menurut Bhagawan Dwija (2009, 3,7), menyatakan : Mpu Kuturan mengembangkan konsep Tri Murti dalam wujud simbol palinggih Kamulan Rong Tiga disetiap perumahan pemujaan Hyang Widhi dalam kedudukan horizontal. Sedangkan Danghyang Nirartha mengembangkan konsep Tri Purusa, pemujaan Hyang Widhi dalam kedudukan vertical (Siwa-Sada Siwa-Parama Siwa).

2. Singgin Wikarman menegaskan, jadi yang dipuja dan disembah di Sanggah Kamulan Rong Tiga tiada lain adalah Ida Sang Hyang Widhi (Tuhan) wujud sebagai Sang Hyang Tri Atma : Atma-Siwatma-Paratma. Wujud sebagai Sang Hyang Tri Purusa : SiwaSada Siwa-Parama Siwa. Sesuai pula dengan Brahma-Wisnu-Iswara. Siwa berfungsi sebagai Guru, maka Hyang Kamulan juga disebut Batara Guru : Guru Purwam (Parama Siwa), Guru Madyam (Sada Siwa), Guru Rupam (Siwa). Dengan demikian sesungguhnya yang dipuja pada Sanggah Kamulan adalah Ida Sang Hyang Widhi dalam wujud sebagai Sang Hyang Tri Atma, Sang Hyang Tri Purusa (Bhatara Guru) dan Sang Hyang Tri Murti (1998, III,12).

3. Tentang Tri Murti, Sara Sastra mengatakan pada jaman Saiwa Gama dan Waisnawa Gama muncul mazab Tri Murti yaitu penyembahan terhadap tiga aspek dewa terpenting : Penciptaan - Pemeliharaan - dan Peleburan diasosiasikan dengan Brahma - Wisnu dan Siwa yang kemudian disebut Tri Murti (II - 41).

\section{Makna Folosofis Pelinggih Sanggah Kamulan pada Masyarakat Hindu Etnis Bali di Kota Mataram}

Mengungkap makna filosofis yang tersirat pada tempat pemujaan sanggah kamulan pada masyarakat Hindu di Kota magtaram tidak terlepas dari hakikat dari pembangunaan tempat pemujaan tersebut. Sanggah kamulan dalam kegiatan keagamaan di lingkungan keluarga sebagai media untuk melakukan pemujaan, baik kehadapn manifestasi Ida Sang 
Hyang Widhi Wasa berupa dewa-dewi juga sekaligus sebagai tempat untuk menstanakan para roh leluhur yang telah disucikan.

Ada beberapa pendapat yang diajukan oleh para ahli berkaitan dengan keberadaan sanggah kamulan. Tjok Rai Sudartha (dalam Suhardana, 2011: 62) dengan tegas mengungkapkan bahwa yang berstana di Sanggah Kamulan adalah Atman atau Pitara atau Sanghyang Guru (maksudnya Guru Rupaka). Lanjut menegaskan, jika ada yang menyatakan bahwa yang berstana di Sanggah kamulan adalah Tri Murthi yaitu Brahma, Wisnu dan Siwa, maka pemikiran itu keliru.

Pendapat Ngurah Nala (dalam Suhardana, 2011: 141) menyebutkan setiap keluarga menempati karang perumahan sendiri untuk menghormati leluhur hendaknya membangun sanggah/merajan. Yang dimaksud dengan sanggah ini adalah suatu areal suci dalam satu lingkup karang perumahan dimana dibangun pelinggih Kamulan untuk memuja Dewa Hyang Leluhur dari satu keluarga.

Mengenai keberadaan pelinggih Rong Kalih menurut Ngurah Nala (dalam Suhardana, 2011: 45) dimana secara purwaloka atau kunadrsta, ada pula yang membangun pelinggih Rong Kalih sebagai pengganti Rong Tiga. Maksud sebenarnya sama yaitu untuk memuja Dewa Hyang atau Dewa Pitara Leluhur.

Lain lagi dengan penjelasan Pandita Mpu Acharya Jaya Dharma Dhaksa Natha, Sweta Indah Cakranegara saat membawakan materi penataran dalam rangka Kegiatan Pelatihan Dasar Kepemangkuan, jurusan Brahma Vidya, STAH Negeri Gede Pudja Mataram, Rabu 26 Agustus 2015 menegaskan, telah mereline delapan sampai sembilan pelinggih Rong Kalih yang tidak ada gunanya. Sebab jika Sang Pitara sudah menresti maka Rong Kalih yang sudah kosong ditempati Buta Cuwil. Untuk itu Sang Pitara - Hyang Dewa harus dilinggayang di Kamulan Rong Tiga, manut doa, agar menyatu dengan asalnya. Atas penegasan tersebut, seorang peserta pelatihan bertanya, bagaimana dengan seorang kakek yang bajingan, pencuri, perampok, pemerkosa yang ditakuti meninggal. Sang cucu kaya raya melaksanakan upacara Pitra sampai selesai tuntas dan sangat sempurna, apa sudah menjamin Sang Pitara menyatu dengan asalnya ? Pandita Mpu dengan cepat tanggap menjawab, "Tidak bisa, itu tergantung karma".

Sedangkan Bendesa K. Tonjaya (1991.12) menjelaskan mengenai Merajan Rong Tiga dengan mensitir beberapa referensi antara lain : 


\section{J. A. Z. Suryosumunar\&I Ketut Narwadha-Sanggah Kamulan sebagai Media Pemujaan pada Masyarakat Hindu di Kota Mataram: Sebuah Kajian Filosofis}

a) Tutur Bang Bungkalan ;

Sanggah diartikan sama dengan Sanggar, Kamulan berarti pemulaan, asal, kawit dan sangkan. Mula adalah mulaning dadi, tiada lain : Ida Sang Hyang Widhi. Jadi Sanggah Kamulan Rong Tiga ditujukan kepada asal yang menjadikan kita ialah Ida Sanghyang Widhi dan manifestasinya.

b) Bungkahing Sundari Terus

Mengapa Sanggah kamulan dibuat Rong Tiga ? Maksudnya : "Kramaning jadmane asanggar kamulan Rong Tiga, witning aksara ika tiga, Ang-Ung-Mang, simbol penciptaan, pemeliharaan, pamrlina asalnya atau Brahma-Wisnu-Siwa. Inilah yang dimaksudkan "kamulaning dadi jadma" atau mulanya terjadi manusia.

c) Pustaka Manusa Yadnya

Setelah orang itu kawin membentuk rumah tangga baru hendaknya membangun Sanggah Kamulan Rong Tiga sebagai tempat bersemayam Sang Hyang Tri Sakti. Ini memberi pengertian manusia berasal dari Sanghyang Tri Murthi (Brahma-Wisnu-Siwa).

d) Pustaka Lebur Gangsa,

Menjelaskan ada praniti (sebuah ajaran), manusia dilahirkan sudah membawa candela, membawa gering (penyakit), kepapaan, hidup dan pasti mati. Praniti mengajarkan supaya manusia membuat Sanggah Kamulan Rong Tiga tempat menyembah ITU (asal kamulan). ITU atau DAT adalah Ida Sanghyang Widhi yang menciptakan, yang member kehidupan (Amrta).

e) Pustaka Angesti Purana dan Korawa Prasada

Menerangkan bahwa Tri Murti/Tri Saktiu perwujudan atau manifestasi Sanghyang Widhi. Jadi mitologinya mengajarkan manusia berhutang hidup kepada Sanghyang Widhi disebut : Dewa Rna, untuk itu harus membayar hutang dengan membuat Sanggah Kamulan Rong Tiga sebagai batu loncatan untuk menyampaikan bhakti.

f) Lontar Gong Wesi

Menyebutkan Sanghyang Widhi bertahta di Pura Dalem bergelar Sanghyang Triyodasasaksi atau Batari Durga Uma Dewi. Mengalih/pindah ke Pura Puseh bergelar Sanghyang Rambut Sedana, dan seterusnya pindah ke Sanggah Kamulan Rong Tiga, sebelah kanan Sang Paratma, kiri Sang Siwatma, di tengah susunatma (kanan-bapak, kiri-ibu, tengahleluhur, dan seterusnya).

g) Didalam Dewa Tatwa 
Membangun Sanggar Kamulan dengan 'pedagingan", di rong kanan perpih besi, aksara Ang simbol Brahma; di rong kiri peripih tembaga, aksara Ung simbol Wisnu ; di rong tengah peripih perak, aksara Mang, simbol Siwa. Jadi makin jelas bahwa Sanggah Kamulan Rong Tiga untuk memuja manifestasi Ida anghyang Widhi sebagai sanghyang Tri Murti (14).

Dalam buku Buana Kosa menyebutkan, Batara Brahma menciptakan, Batara Wisnu memelihara (menjaga), Batara Rudra melebur. Dewa yang tiga itu menjadi pelindung dunia (Tim Penerjemah, VI,25).

Sesungguhnyalah masyarakat Hindu patut berbangga sebagai penganut Weda. Weda maha sempurna. Yang ada di Weda, ada juga ditempat lain, tidak ada di tempat lain, ada di Weda. Keagungan Weda telah pula dijabarkan atau dituangkan dalam bentuk wira carita seperti epos Mahabarata dan Ramayana. Didalam Mahabarata, buku pertama Adi parwa ada kisah Sang Jaratkaru yang tergantung pada sebatang bambu dengan kepala dibawah di atas jurang yang sangat dalam dan pangkal bambu terus digigit oleh tikus. Keadaan yang mengharukan tersebut terlihat oleh seorang brahmacari yang bernama sama yakni Jaratkaru. Setelah mengetahui yang tergantung adalah leluhurnya dengan serta merta hendak diberikan semua "yasa kerti" atau hasil amal baiknya untuk mengangkat kesengsaraan leluhurnya. Tapi maksud baik Sang Jaratkaru tidak diterima leluhurnya. Hal tersebut manut ujar-ujar Sarasamuscaya nomor 4 yang menegaskan "berbahagialah jadi manusia, sebab dapat ngentas diri sendiri dari samsara (punarbhawa). Bahkan leluhurnya menyuruh Sang Jaratkaru kembali ke dunia dan segera kawin. Ini berarti Sang Jaratkaru yang brahmacari diharuskan menjalani tahapan-tahapan Catur Asrama. Melaksanakan catur asrama berarti bergulat dengan Catur Purusa Artha yang pada ujung-ujungnya juga ke karma. Dan karma (karma phala) harus dibayar dengan reinkarnasi demi reinkarnasi.

\section{Kesimpulan}

Berdasarkan hasil analisis data yang telah dilakukan maka ada beberapa simpulan yang dapat ditarik. Pertama, bentuk sanggah kamulan yang ada pada masyarakat Hindu di Kota Mataram ada yang berupa bangunan rong tiga saka dua, ada rong tiga saka nem, rong tiga turus lumbung, dan ada berupa rong kalih. Bentuk-bentuk tersebut sangat erat kaitannya dengan keyakinan (sraddha) dari umat Hindu sebagai media pemujaan terhadap Manifestasi Ida Sang Hyang Widhi maupun Hyang Dewa Pitara/Leluhur. Kedua, fungsi sanggah kamulan adalah Rong Tiga adalah Ida Sang Hyang Widhi (Tuhan) wujud sebagai Sang 


\section{J. A. Z. Suryosumunar\&I Ketut Narwadha-Sanggah Kamulan sebagai Media Pemujaan pada Masyarakat Hindu di Kota Mataram: Sebuah Kajian Filosofis}

Hyang Tri Atma : Atma-Siwatma-Paratma. Wujud sebagai Sang Hyang Tri Purusa : SiwaSada Siwa-Parama Siwa. Sesuai pula dengan Brahma-Wisnu-Iswara. Siwa berfungsi sebagai Guru, maka Hyang Kamulan juga disebut Batara Guru : Guru Purwam (Parama Siwa), Guru Madyam (Sada Siwa), Guru Rupam (Siwa). Dengan demikian sesungguhnya yang dipuja pada Sanggah Kamulan adalah Ida Sang Hyang Widhi dalam wujud sebagai Sang Hyang Tri Atma, Sang Hyang Tri Purusa (Bhatara Guru) dan Sang Hyang Tri Murti disamping juga sebagai media pemujaan Hyang Dewa Pitara/Leluhur. Ketiga, makna filosofi sanggah kamulan berkaitan dengan hakikat dasar yang menjadi landasan dalam pembangunan pelinggih sanggah kamulan yakni sebagaimana gagasan Mpu Kuturan yang telah meminit palinggih Sanggah Kamulan Rong Tiga merupakan manifestasi Ida Sanghyang Widhi dimana Brahma sebagai pencipta dengan lamak warna merah, Wisnu sebagai pemelihara dengan lamak warna hitam dan Iswara sebagai pemralina dengan lamak warna putih dinamakan Sanghyang Tri Murti.

\section{Daftar Pustaka}

Arikunto Suharsini, Prof., Dr. 2010. Prosedur Penelitian, Jakarta Rineka Cipta

Bendesa K. Tonjaya, I Nyoman Gd. 1991. Riwayat Empu Kuturan, Denpasar, Toko Buku Ria Dwija Bhagawan, 2009, Hindu Dalam Wacana, Bali Centris, Bahan Ajar Siwa Sidhanta

Kadjeng, I Nyoman Dkk, 1991, Sarasamuscaya, Jakarta, Yayasan Dharma Sarathi

Mahardika Gede, 2009, Tesis Analisis Upacara Rajaswala di Banjar Bekasi (Kajian Bentuk Fungsi Makna), Denpasar.

Margono, 2004, Metode Penelitian Pendidikan, Jakarta Renika Cipta.

Mulyono, Edi 2012 Belajar Hermeneutika, Jogyakarta : IRCiSod

Mirta Astawa, I Wayan, 2003, Panca Sradha, Departemen Agama RI, Dirjen Bimas Hindu dan Budha, Jakarta.

Myers, Michael D, 2009, Qualitative Research in Business and Management India, SAGE Publications India Prt, Ltd

Nasir, Moh., PhD, 1999, Metode Penelitian, Jakarta, Ghalia Indonesia.

Palmer, Richard E. 2005, Hermeneutika Teori Baru Mengenai Interprestasi, Yogyakarta, Pustaka Pelajar

Noorzeha, F. (2019). Pemikiran Sir Sayyid Ahmad Khan "Pembaharuan di India" Relevansinya dengan Ideologi Islam Puritan, Moderat dan Sinkretisme dalam Masyarakat. Sophia Dharma: Jurnal Filsafat Agama Hindu dan Masyarakat, 2(1), 6277.

Pelly Usman dan Asih Minarti, 1994, Teori-Teori Sosial Budaya, Jakarta, Proyek Pembinaan dan Peningkatan Mutu Tenaga Kependidikan Ditjen Dikti Depdikbud.

Piliang Yasraf Amir, 2003, Hipersemiotik Tafsir Cultutral Studies Atas Matinya Makna, Yogyakarta, Jalasutra.

Punyatmaja Oka, I.B. Drs, 1992, Panca Crada, Jakarta, Yayasan Dharma Sarathi.

Raharjo, H. Mudjia, 2008, Dasar-dasar Hermeneutika Antara Intensionalisme dan Gadameriam, Yogyakarta, AR-Ruzz Media. 
Sara Sastra Gde Drs, Msi, Bahan Ajar Bhujangga Waisnawa dan Sang Trini.

Singgin Wikarman, I Nyoman Drs, 1998, Sanggah Kamulan (Fungsi dan Pengertiannya), Surabaya Paramita.

Soebandi, Ktut, 1985, Berbhakti Kepada Kawitan (Leluhur) adalah Paramo Dharmah, Denpasar, Yayasan Adhi Sapta Kerthi.

Sugiyono, 2009, Metode Penelitian Kualitatif-Kuantitatif dan R D, Bandung-Alfa Beta.

Suhardana, K.M., Drs,2011, Menjangan Sakaluang, Himpunan Berbagai Tulisan, Surabaya, Paramita.

Tim Penerjemah, 1994, Buana Kosa, Denpasar, Upada Sastra

Tim Penyususun, 1994, Pelajaran Agama Hindu Untuk Sekolah Menengah Tingkat Atas Kelas III, Jakarta, Hanuman Sakti.

Titib, I Made Dr, 2003, Teologi dan Simbol-Simbol Dalam Agama Hindu, Surabaya, Paramitha

Wirawan Ardhi, I Wayan Dr, SPd, Sag, MSi, 2014, Buku Bahan Ajar Filsafat Nusantara. Yudhiantara, Kadek, 2003, Dasaksara Saiwa Sidhanta dan Kanda Pat, Surabaya, Paramitha 